\title{
La legislación cooperativa en Argentina
}

\author{
Dante Cracogna \\ Universidad de Buenos Aires \\ dcracogna@estudiocracogna.com.ar
}

doi: http://dx.doi.org/10.18543/dec-18-2021pp53-85

Recibido: 22.06.2021

Aceptado: 06.09.2021

Sumario: 1. Antecedentes.-2. La Ley 20.337.-3. El Código Civil y Comercial.-4. Naturaleza y objeto.-5. Constitución.-6. Asociados.-7. Capital.-8. Excedentes, fondos y reservas.-9. Estructura orgánica: 9.1. Asamblea. 9.2. Consejo de administración. 9.3. Sindicatura y auditoría.-10. Integración.-11. Disolución.-12. Fiscalización pública.-13. Conclusión.-Bibliografía.

Resumen: El artículo describe sintéticamente el régimen legal de las cooperativas en Argentina comenzando por sus antecedentes históricos a partir del Código de Comercio de 1889 y un planteo general de la ley vigente en la materia. Seguidamente se exponen los principales institutos jurídicos siguiendo la estructura de la Ley 20.337 y poniendo énfasis en aquéllos que distinguen claramente a las cooperativas de otras formas jurídicas de organización colectiva. Se analiza la incidencia del Código Civil y Comercial que rige a partir de 2015 sobre la legislación cooperativa como así también la aplicación supletoria de las disposiciones sobre sociedades anónimas contenidas en la Ley General de Sociedades. Especial atención merecen la caracterización de las cooperativas, el acto cooperativo, el régimen económico, los órganos sociales y la integración cooperativa.

Palabras clave: legislación cooperativa, acto cooperativo, Código Civil y Comercial, ley argentina de cooperativas.

Abstract: This article describes in a synthetic way the legal treatment of cooperatives in Argentine starting from the Code of Commerce enacted in 1889 to the present law on cooperatives. It provides a vision of the main features of the cooperatives following the structure of Law 20.337 which is the general law of cooperatives in the country. It emphasizes the aspects that make the difference between cooperatives and for-profit societies. The impact of the new Civil and Commercial Code of 2015 on the legal framework for cooperatives is considered as well as the subsidiary incidence of the regulations of the General Law of Societies. Special attention is paid to the notion of cooperative act, the economic regimen, the governance structure of cooperatives and the regulation of cooperation among cooperatives.

Keywords: cooperative legislation, cooperative act, Civil and Commercial Code, Argentine law on cooperatives. 


\section{Antecedentes}

La legislación cooperativa en Argentina surgió con posterioridad a la aparición de las cooperativas. En efecto, las primeras cooperativas fueron creadas en el último tercio del siglo XIX. Eran principalmente cooperativas de consumo que seguían el modelo europeo traído por los inmigrantes de ese origen que llegaron al país estimulados por los regímenes de promoción de la colonización del extenso y prácticamente vacío territorio nacional. Dentro de las políticas implementadas por los gobiernos posteriores a la organización nacional se encontraba la de poblar el territorio promoviendo la inmigración europea, tal como postulaba la Constitución sancionada en 1853. Esos inmigrantes trajeron la experiencia cooperativa de sus países de origen y la desarrollaron al calor de las circunstancias de sus nuevos lugares de radicación.

Las primeras cooperativas nacieron cuando no existía ley de cooperativas ni se ocupaban de ellas los códigos de comercio y civil sancionados en 1862 y 1869, respectivamente. De manera que esas primeras experiencias tuvieron que adoptar distintas formas jurídicas conforme con las que se organizaron preservando rasgos propios de las cooperativas.

Fue recién con la reforma del Código de Comercio sancionada en 1889 que las cooperativas adquirieron reconocimiento jurídico específico mediante su regulación en tres artículos que trataban acerca de ellas. De manera reveladora, el informe de la Comisión de Códigos del Senado de la Nación que despachó el proyecto de reforma señalaba que se consideró conveniente legislar acerca de las cooperativas puesto que ellas habían comenzado a aparecer prometiendo el beneficio de su desarrollo futuro. Claramente, pues, el legislador se hizo cargo de una realidad económica y social que ya existía; y así lo reconoció expresamente. No obstante, las escuetas disposiciones del Código de Comercio relativas a las cooperativas eran insuficientes para su adecuada regulación'1.

Pese a la señalada insuficiencia legal, las cooperativas continuaron desarrollándose al amparo de dichas normas pasando a tener una significativa importancia las cooperativas agrarias. En 1926, después de 36 años de vigencia del Código de Comercio reformado, cuando ya las cooperativas habían alcanzado un crecimiento considerable —con la existencia, incluso, de cooperativas de segundo grado- se sancionó la primera ley de cooperativas bajo el $n .{ }^{\circ} 11.388$ culminando una serie

1 Pastorino, Roberto Jorge, Orígenes del Derecho Cooperativo argentino, Intercoop, Buenos Aires, 1998, p. 30 y ss. 
de intentos realizados para su regulación mediante proyectos presentados por distintos senadores y diputados, además del Poder Ejecutivo. Esta ley, sancionada contemporáneamente con otra orientada especialmente al fomento de las cooperativas agrarias, significó un decidido espaldarazo al crecimiento de las cooperativas al dotarlas de un régimen actualizado y acorde con los genuinos caracteres que las definen. Incluso sirvió eficazmente para depurar algunas manifestaciones espúreas que habían aparecido, estableciendo la aplicación de sanciones a las entidades que se denominaban cooperativas sin sujetarse a sus disposiciones ${ }^{2}$.

Por fin, el tercer momento de la legislación cooperativa nacional está constituido por la sanción en 1973 de la Ley 20.337, todavía vigente, que vino a sustituir a la ley de 1926. La actual ley, cuyo proyecto fue elaborado con participación del movimiento cooperativo, significó un decidido avance en la materia consolidando la disciplina jurídica de las cooperativas a tono con la doctrina y los principios cooperativos y las exigencias de las nuevas circunstancias del quehacer empresarial.

En síntesis, las cooperativas precedieron a su legislación y la evolución de ésta consta de tres etapas: las normas del Código de Comercio, vigentes durante 36 años; la Ley 11.388 que rigió a lo largo de 47 años y, por fin, la actual Ley 20.337 que lleva 48 en vigor.

\section{La Ley $20.337^{3}$}

La Constitución Nacional no contiene mención alguna de las cooperativas; cuando se sancionó (1853) las cooperativas no existían y sus posteriores reformas fueron limitadas y puntuales. Por otra parte, al efectuarse una importante reforma en 1994, pese a existir un movimiento cooperativo desarrollado, el constituyente no consideró necesario referirse a él. Tal omisión no fue óbice para que las cooperativas se expandieran en numerosos sectores económicos y ámbitos geográficos merced a que la Constitución reconoce con amplitud el derecho de asociación y a la existencia de una legislación apropiada.

2 Rodríguez Gomes, Federico, abunda en consideraciones acerca de las características de la Ley 11.388 y reproduce el texto del informe de la Comisión de Códigos del Senado que despachó el respectivo proyecto de ley, el cual demuestra el profundo conocimiento que sus autores tenían del tema, avalado por una amplia investigación del derecho comparado (La sociedad cooperativa, 2. ${ }^{a}$ ed., Hachette, Buenos Aires, 1955, p. 311 y ss).

3 En adelante las referencias a esta ley se harán como LC. 
La Ley 11.388 sirvió adecuadamente al desarrollo de un sano movimiento cooperativo durante casi cinco décadas y los escasos reclamos para que fuera reformada se fundaban, básicamente, en la conveniencia de una actualización. Sin embargo, la situación cambió cuando en 1972 se dictó la Ley de Sociedades Comerciales que introdujo importantes modificaciones en el régimen de las sociedades anónimas que era supletoriamente aplicable a las cooperativas. En efecto, la vieja Ley 11.388 se limitaba a reglar los aspectos fundamentales de las cooperativas y declaraba subsidiariamente aplicables las normas sobre las sociedades anónimas, lo cual devino inconveniente cuando se reformó sustancialmente la disciplina de estas últimas.

La apuntada circunstancia motivó que el propio movimiento cooperativo - a cuyo progreso había servido eficazmente - propugnara la modificación de la Ley 11.388 a fin de evitar los problemas que traería aparejados el nuevo régimen de las sociedades anónimas. A la vez, se aprovecharía para efectuar una prudente actualización de su contenido teniendo en cuenta, entre otras cosas, la reformulación de los principios cooperativos realizada por la Alianza Cooperativa Internacional en $1966^{4}$, además de otros aspectos puntuales. Para elaborar el respectivo proyecto se designó una comisión de la que participaron representantes de las organizaciones superiores de integración cooperativa.

De todo lo anterior resultó una nueva ley de cooperativas mucho más extensa que su predecesora, orgánica y sistemáticamente concebida, conteniendo trece capítulos con ciento veinte artículos y con una terminología respetuosa de la naturaleza propia de las cooperativas. Su rigor doctrinario se halla garantizado por su fidelidad a los principios cooperativos entonces vigentes. La extensa exposición de motivos que la comisión redactora acompañó con el proyecto ilustra cabalmente acerca de las fuentes, sentido y alcances de cada una de sus disposiciones.

Si bien la nueva ley mantiene la aplicación subsidiaria de las normas sobre sociedades anónimas a fin de no recargar excesivamente su texto, la amplitud de su contenido evita que dicha subsidiaridad invada terreno que pueda comprometer los rasgos propios de las cooperativas.

Se trata de una ley de alcance nacional puesto que si bien la organización política del país es federal, la Constitución Nacional reserva a la Nación la potestad de legislar sobre el derecho de fondo civil y co-

4 Alianza Cooperativa Internacional, Nuevos enfoques de los principios cooperativos en el mundo, Idelcoop, Rosario, 1981. 
mercial, dejando librada sólo su aplicación a los tribunales provinciales. De manera que se trata de una ley única que rige en todo el territorio del país y es, además, de carácter general, pues rige a todas las cooperativas cualquiera sea su objeto social o actividad específica. A pesar de que existieron proyectos para regular de manera especial a las cooperativas de trabajo y de crédito, hasta el momento no han prosperado, por lo que la LC sigue siendo única y general.

A diferencia de lo que había sucedido anteriormente, la actual ley no forma parte de ningún código. Las primeras normas sobre la materia integraban el Código de Comercio como artículos 391, 392 y 394, en tanto que la Ley 11.388 se halla incorporada como un capítulo especial del mismo código. No ocurre de igual manera con la ley actual, que tampoco se incorporó al Código Civil. Como se verá más adelante, ello constituye uno de los motivos fundamentales para definir la naturaleza jurídica propia de las cooperativas, sin perjuicio de la unificación del derecho privado mediante la sanción del Código Civil y Comercial en 2015.

A lo largo de casi medio siglo de vigencia la LC demostró resultar un instrumento idóneo para reglar la organización y el funcionamiento de las cooperativas. Prueba de ello es que prácticamente no sufrió modificaciones ${ }^{5}$ durante ese extenso período y que el propio movimiento cooperativo manifestó reiteradamente su oposición a la reforma ${ }^{6}$. La doctrina y la jurisprudencia, por su parte, no han expresado críticas relevantes. La razón de haber perdurado incólume durante ese dilatado lapso pese a los cambios políticos y económicos que se han producido en el país puede encontrarse en su carácter amplio y no reglamentarista, respetuoso tanto de los principios como de la autonomía de las cooperativas a las que preserva de la injerencia estatal y permite una actuación libre y voluntaria.

Los problemas legales que las cooperativas enfrentan no surgen de la LC sino que son provocados por otros regímenes que inciden sobre ellas o que se les aplican inapropiadamente, como las limitaciones a

5 Sólo dos leyes modificaron la LC, a saber: la ley 22.816 que sólo introdujo ligeras modificaciones en materia de sanciones y la ley 25.017 que dispuso una limitación a la baja de asociados resuelta por la asamblea o el consejo de administración cuando supere el $10 \%$ de los asociados, pero supeditó su vigencia a la reglamentación que debía dictarse al respecto, lo cual nunca ocurrió.

6 Los Congresos Argentinos de la Cooperación que se realizaron con posterioridad a la sanción de la LC invariablemente se pronunciaron en favor de su mantenimiento y cuando la autoridad de aplicación de la Ley de Cooperativas promovió su reforma mediante un proyecto llamado «Ley Federal de Cooperativas y Mutuales» en 2014, el movimiento cooperativo en forma prácticamente unánime se pronunció en contra. 
ciertas actividades, la aplicación de las legislación laboral a las cooperativas de trabajo y el tratamiento fiscal inadecuado; además de la acción de ciertos organismos estatales que no toman en consideración su particular naturaleza. Las únicas adecuaciones que se reclaman tienen que ver con la necesidad de contar un régimen especial para las cooperativas de trabajo dentro del marco general de la LC y una regulación simplificada para las pequeñas cooperativas.

\section{El Código Civil y Comercial}

Después de años de proyectos de unificación del derecho privado no concretados, en 2015 entró en vigencia el Código Civil y Comercial que sustituyó a los antiguos códigos que trataban cada una de esas materias. Además de la unificación, el nuevo Código introdujo importantes reformas en el campo de ambas disciplinas.

Sin embargo, como señalan los Fundamentos elaborados por la comisión redactora, el nuevo cuerpo legal no altera los llamados «microsistemas normativos autosuficientes» consistentes en leyes que tratan en forma especial determinados institutos del derecho privado, tales como la ley de sociedades comerciales - que pasa a denominarse ley general de sociedades-, la ley de concursos, la ley de seguros, la ley de mutuales y la ley de cooperativas. Empero, aunque dichas leyes mantengan su vigencia, la sanción del nuevo Código que rige a todo el derecho privado provocó un reacomodamiento de las disposiciones de cada una de ellas para su ubicación armónica dentro del nuevo sistema. Este proceso aun se halla en marcha mediante la actuación de los tribunales y la contribución de la doctrina.

El Código Civil y Comercial, contiene en el Libro Primero (Parte General) un título íntegramente dedicado a las personas jurídicas - que no existía en los códigos anteriores - por lo que resulta de particular importancia el orden de prelación para la aplicación de dichas normas y de las contenidas en las leyes especiales de sociedades, mutuales y cooperativas, además de la fuerza jurígena de la voluntad de sus integrantes. La llave maestra de ese orden de prelación se halla en el art. 150 que dispone que las personas jurídicas privadas se rigen, en primer lugar, por las normas imperativas de su ley especial; es decir por la LC en el caso de las cooperativas. En segundo término, no existiendo normas imperativas en la ley especial o en el Código Civil y Comercial, rigen las normas del acto constitutivo y sus modificaciones; vale decir, el estatuto de la cooperativa, que es la expresión de la voluntad de sus integrantes. Por último, en ausencia de los dos niveles normativos anterio- 
res, se aplican las normas supletorias de las respectivas leyes especiales (la LC en este caso) o, en su defecto, las del título del Código Civil y Comercial relativo a las personas jurídicas privadas en general.

No obstante, en el caso de las cooperativas existe una complicación adicional derivada de la norma de la LC que determina que para ellas rigen supletoriamente las disposiciones relativas a las sociedades anónimas en cuanto se concilien con las disposiciones de la LC y la naturaleza de las cooperativas. En consecuencia, para que sean aplicables las disposiciones sobre sociedades anónimas deben cumplirse los siguientes requisitos: a) que no existan disposiciones imperativas ni supletorias de la voluntad de las partes en la LC; b) que las normas sobre sociedades anónimas sean compatibles con las de la LC y c) que dichas normas se concilien con la naturaleza de las cooperativas.

En conclusión, del análisis de las normas del Código Civil y Comercial sobre las personas jurídicas privadas se desprende que no existen disposiciones que puedan alterar sustancialmente el régimen legal de las cooperativas por cuanto la LC regla de manera imperativa sus aspectos fundamentales; consiguientemente, la aplicación del nuevo Código no ha provocado modificaciones en su desenvolvimiento ${ }^{7}$. En cambio, existe en el nuevo Código un artículo que ha venido a ratificar la orientación doctrinaria que sostiene la singularidad de las cooperativas como entidades diferentes de la sociedades y de las asociaciones. Efectivamente, el art. 148 del nuevo Código cuando enumera las personas jurídicas privadas menciona en forma diferenciada a las sociedades, las asociaciones y las cooperativas, además de las mutuales, las fundaciones y otras, con lo cual deja claramente determinado que se trata de personas jurídicas diferentes dando así un paso fundamental en la afirmación de la naturaleza propia y distinta de las cooperativas.

\section{Naturaleza y objeto}

El primer capítulo de la LC — de sólo seis artículos- constituye el núcleo significativo que brinda sentido a la totalidad de las disposiciones que integran su texto.

El concepto de cooperativa que la ley incorpora consiste en afirmar que son «entidades fundadas en el esfuerzo propio y la ayuda mutua para organizar y prestar servicios». Surge clara la diferencia con las

7 Cracogna, Dante, «Las cooperativas en el marco del Código Civil y Comercial», Revista de Derecho Comercial y de las Obligaciones, n. ${ }^{\circ} 273$, Buenos Aires, julio-agosto 2015, p. 1047 y ss. 
sociedades que reúnen capital que para la obtención de lucro o incrementar el valor de la inversión de sus socios; las cooperativas, en cambio, organizan servicios sobre la base del esfuerzo propio y de la ayuda mutua, lo cual define su peculiar naturaleza.

El amplio concepto del art. 2 LC cobija a toda clase de cooperativas; sin embargo, su misma amplitud hace necesario acotarlo para evitar confusión con otras entidades tales como las asociaciones y las mutuales que tienen ciertos rasgos similares. De allí que el mismo artículo puntualice que deben reunir una serie de caracteres entre los cuales se encuentran los principios cooperativos que habían sido formulados por el Congreso de la $\mathrm{ACl}$ de 1966, si bien no los menciona como tales ${ }^{8}$. Asimismo, dichos caracteres pueden vincularse con los principios incluidos en la Declaración sobre la Identidad Cooperativa de 1995, a saber: asociación voluntaria y abierta (incs. $1 .{ }^{\circ}, 2 .^{\circ}$ y $7 . .^{\circ}$ ); control democrático por los asociados (inc. $3^{\circ}$ ); participación económica de los asociados (incs. $4 .^{\circ}, 6^{\circ}$ y 12 ); autonomía e independencia (incs. $3 .^{\circ}$ y $7 .^{\circ}$ ); educación, capacitación e información (inc. $8^{\circ}$ ); cooperación entre cooperativas (inc. 9. ${ }^{\circ}$ ); preocupación por la comunidad (incs. 8. ${ }^{\circ}, 10$ y 12$)^{9}$.

Los restantes incisos del art. 2 mantienen ciertos rasgos que las cooperativas tienen tradicionalmente reconocidos en el derecho argentino: variabilidad del capital y duración ilimitada; número mínimo de diez asociados, salvo excepciones que admitiera la autoridad de aplicación; limitación de la responsabilidad de los asociados; destino desinteresado del sobrante patrimonial en caso de liquidación.

Una disposición especial es la que permite la prestación de servicios a no asociados en las condiciones que establezca la autoridad de aplicación y con el recaudo de que los excedentes derivados de esas operaciones se destinen a una cuenta especial de reserva de carácter irrepartible, como todas las reservas previstas por la ley.

Las notas caracterizantes contenidas en el art. 2 constituyen una suerte de portada o síntesis del régimen de las cooperativas que se va desarrollando posteriormente a lo largo de los sucesivos capítulos de la

8 Sin perjuicio de que, como afirma la Exposición de Motivos, la ley incorpora los principios cooperativos declarados por la $\mathrm{ACl}$ en su XXIII Congreso realizado pocos años antes (Viena 1966), los caracteres previstos por el art. 2 dan cabida también a los contenidos en la Declaración sobre la Identidad Cooperativa. Cfr. Alianza Cooperativa Internacional, Los principios cooperativos para el siglo XXI, Intercoop, Buenos Aires, 1996.

9 Resulta ilustrativo acerca del tema de los principios en la conceptualización de las cooperativas el desarrollo de Alfonso Sánchez, Rosalía, «Los principios cooperativos como principios configuradores de la forma social cooperativa», Revista Jurídica de Economía Social y Cooperativa, n. ${ }^{\circ}$ 27, CIRIEC-España, Valencia, diciembre 2015, p. 49 y ss. 
ley. Tales notas, junto con los restantes artículos del capítulo primero, definen la peculiar naturaleza de aquéllas.

La ley impone que la denominación social incluya la palabra «cooperativa» $y$, por otro lado, sanciona el uso indebido de ésta por parte de entidades que no reúnan los caracteres que la ley exige.

Norma de trascendente importancia es la que consagra la noción del "acto cooperativo» (art. 4) verdadero meollo de la teoría del derecho cooperativo como disciplina autónoma y diferenciada, más allá de la autonomía legislativa. El acto cooperativo existe como realidad económica y social por cuanto se trata de la relación que tiene lugar entre el asociado y la cooperativa en la realización del objeto social de ésta, que no es otro que el servicio; es una relación singular, diferente de otras, que constituye un acto jurídico específico. Pero en este caso, la propia ley le brinda reconocimiento con lo cual no puede asimilarse a otros actos jurídicos y adquiere contornos propios; no es un acto de comercio ni civil ni administrativo; es un acto específicamente cooperativo y su consecuencia es la sujeción a las normas del estatuto y las propias del derecho cooperativo, dejando espacio sólo a la aplicación residual de las normas que rigen a los institutos jurídicos afines al objeto social de la cooperativa (consumo, crédito, comercialización, vivienda, trabajo, etc.).

Desde la sanción de la LC la jurisprudencia se ha ido haciendo cargo de este instituto en pronunciamientos que contribuyen a perfilar sus efectos, diferenciándolo de otros actos jurídicos. Pero debe admitirse que todavía, pese al tiempo de su vigencia, no ha logrado cabal reconocimiento jurisprudencial y doctrinario debido, en buena medida, a que el tema no ha sido materia de enseñanza universitaria y a la carencia de suficiente producción teórica al respecto ${ }^{10}$.

A diferencia de otras legislaciones, la ley acoge una noción amplia del acto cooperativo pues no solamente considera tal al realizado entre las cooperativas y sus asociados y por aquéllas entre sí en el cum-

10 Sobre el acto cooperativo y su recepción jurisprudencial: Rezzónico, Alberto Edmundo, «El acto cooperativo. Noción, contenido y alcances. Su incorporación al derecho positivo nacional», Congreso Continental de Derecho Cooperativo. Montevideo, 16-18 de noviembre de 2016, Intercoop, Buenos Aires, 2018, p. 53 y ss; Vallati, Jorge Armando, «El acto cooperativo. Recepción legislativa y jurisprudencial. Efectos en la cooperativa de consumo», Congreso Continental de Derecho Cooperativo. San José de Costa Rica, 20 al 22 de noviembre de 2019, Cooperativas de las Américas, San José, 2020, p. 137 y ss. De especial interés sobre el tema con un enfoque español resulta Vargas Vasserot, Carlos, «El acto cooperativo en el derecho español», Revista Jurídica de Economía Social y Cooperativa, n. ${ }^{\circ} 37$, CIRIEC-España, Valencia, diciembre 2020, p. 9 y ss. 
plimiento de su objeto social sino también, respecto de las cooperativas, a los que con idéntica finalidad realicen con otras personas; vale decir a aquéllos que resulten necesarios para realizar su objeto social: por ejemplo la adquisición de mercaderías a terceros por parte de las cooperativas de consumo para su distribución entre los asociados o la venta a terceros de los productos de sus asociados por parte de las cooperativas agrarias.

En síntesis, los elementos que caracterizan el acto cooperativo son:

a) los sujetos que intervienen (la cooperativa y sus asociados);

b) el objeto (la realización del objeto social): y

c) la causa (propósito de servicio y consiguiente ausencia de fin lucrativo).

La doctrina ha criticado el acto unilateralmente cooperativo previsto en el segundo párrafo del art. 4, pero también se ha señalado que la cooperativa no podría realizar sino actos cooperativos (directos o internos con los asociados e indirectos o externos con terceros) para poder cumplir su objeto sociall1.

El objeto de la cooperativa es la prestación de servicios a sus asociados y la LC no pone limitación alguna a cuáles sean esos servicios; de manera que las cooperativas tienen abierta la posibilidad de realizar cualquier actividad en beneficio de sus asociados, siempre que se halla contenida en el objeto social previsto en su estatuto y que su denominación social no incluya expresiones que supongan un campo de operaciones diferente. Las limitaciones que existen para la actuación de las cooperativas en ciertas actividades surgen de otras leyes pero no de la ley de cooperativas.

En línea con el concepto de cooperativa establecido en el art. 2 y con la noción de acto cooperativo del art. 4, la LC prescribe que las cooperativas «no pueden transformarse en sociedades comerciales o asociaciones civiles» (art. 6) y fulmina de nulidad a toda resolución en contrario. Esta categórica prohibición viene a probar que las cooperativas no son sociedades ni asociaciones, puesto que no pueden transformarse en ellas, con lo cual sólo queda admitir que constituyen una categoría diferente. Esta conclusión se halla reforzada por la norma del art. 148 del Código Civil y Comercial, antes mencionada, según la cual las cooperativas son personas jurídicas privadas diferentes de las sociedades y de las asociaciones. Obviamente, esta conclusión ratifica su na-

11 Es lo que Münkner ha puntualizado como counter-transactions (Münkner, Hans-H., "Germany», Cracogna, Dante-Fici, Antonio-Henrÿ, Hagen (Editors), International Handbook of Cooperative Law, Springer, Heidelberg, 2013, p. 418). 
turaleza distinta y da apoyo a la teoría del derecho cooperativo como disciplina autónoma con un objeto propio ${ }^{12}$.

En el mismo capítulo se resuelve una cuestión que había sido materia de controversia durante la vigencia de la anterior ley de cooperativas: se faculta a las cooperativas para asociarse con personas de otro carácter jurídico (sociedades, asociaciones, mutuales, etc.) con sujeción al cumplimiento de dos condiciones, a saber: que sea conveniente para su objeto social y que no se desvirtúe su propósito de servicio $^{13}$. De esa suerte, las cooperativas pueden actuar sin limitaciones en el terreno económico, sea formando otras figuras jurídicas o celebrando contratos empresariales para actividades que faciliten la realización de su objeto social. Esta permisión despeja dudas acerca de las posibilidades de actuación de las cooperativas potenciando su capacidad operativa en el escenario de una economía competitiva recurriendo a mecanismos de complementación que permitan superar distintas limitaciones.

En suma, la caracterización de la cooperativa; su objeto de servicio; el acto cooperativo y la prohibición de transformación, determinan una naturaleza singular de esta figura dentro del panorama del derecho nacional.

\section{Constitución}

La LC determina que las cooperativas son sujetos de derecho con los alcances previstos en ella; vale decir que son personas jurídicas distintas de los asociados que las integran, tal como el Código Civil y Comercial establece para las personas jurídicas privadas en general. Dicho carácter es adquirido mediante la autorización para funcionar y la inscripción en el registro que lleva la autoridad de aplicación.

12 La terminante prohibición de transformación que consagra el art. 6 tiene asimismo una razón práctica y ética que consiste en evitar que por esa vía las reservas irrepartibles de la cooperativa pasen a formar parte del patrimonio de la nueva sociedad y puedan ser apropiadas por los socios de ésta. La prohibición legal, en cambio, impone que la cooperativa deba liquidarse y destinar el sobrante patrimonial resultante al Fisco para promoción cooperativa como establecen los arts. 94 y 102 LC. A continuación los asociados interesados podrán formar una nueva sociedad que nada tendrá que ver jurídicamente con la cooperativa preexistente.

13 De allí que la correcta caracterización de las cooperativas revista importante significado, incluso en el aspecto tributario. Ver al respecto: Atxabal Rada, Alberto, «La identidad cooperativa como justificación de un tratamiento fiscal diferenciado», Boletín de la Asociación Internacional de Derecho Cooperativo, n. ${ }^{\circ}$ 50, Deusto, 2016, p. 285 y ss. 
El registro de cooperativas es único para todo el país y se halla a cargo del Instituto Nacional de Asociativismo y Economía Social $(\text { INAES })^{14}$. Se trata de un registro especial, diferente del que corresponde a las sociedades y las asociaciones. Para obtener la inscripción debe presentarse el acta de constitución - que no requiere escritura pública - la cual debe contener el estatuto, la suscripción e integración de cuotas sociales (capital) y la designación de los integrantes del consejo de administración y del síndico (órgano de fiscalización interna) ${ }^{15}$, además de los datos de identificación de los fundadores. El acta debe contar con las firmas certificadas de los miembros del consejo de administración. A ella debe agregarse una constancia del depósito bancario de la vigésima parte del capital suscrito. La autoridad de aplicación efectúa el control de legalidad y, de no haber observaciones o una vez subsanadas éstas, otorga la autorización para funcionar y efectúa la inscripción en el registro otorgando los respectivos testimonios y certificados.

La ley es muy precisa en cuanto al contenido que debe tener el estatuto por lo que éste se convierte en el instrumento que rige prácticamente de manera integral la organización y el funcionamiento de la cooperativa como así también su eventual disolución y liquidación, obviamente en concordancia con las disposiciones legales. A fin de facilitar y orientar la tarea de los fundadores, la autoridad de aplicación ofrece un estatuto tipo con cláusulas adaptadas a las diferentes clases de cooperativas (consumo, agraria, vivienda, trabajo, etc). Como todos los modelos, su adopción reduce el tiempo del trámite pero, a la vez, suele no adecuarse a las características propias de cada cooperativa en particular.

Como la constitución legal solamente queda formalizada una vez autorizada e inscripta la cooperativa, los fundadores son ilimitada y solidariamente responsables por los actos practicados y los bienes recibidos hasta que la cooperativa quede regularmente constituida. Esta severa disposición se enfrenta con el problema de la demora en la que suele incurrir la autoridad de aplicación para concluir el trámite. En efecto, si bien la ley establece un plazo de sesenta días para finalizar el procedimiento, con frecuencia ese plazo es excedido $-\mathrm{y}$ a veces con largueza - lo cual desalienta a los fundadores.

14 En el capítulo 12 se trata acerca de este organismo, al que a lo largo del texto se lo menciona como la autoridad de aplicación de la ley de cooperativas.

15 Acerca de la figura del síndico — denominación única en la legislación regional— se trata en el capítulo 9. 
A los requisitos establecidos por la ley para la constitución la autoridad de aplicación agrega algunos otros, especialmente un estudio de factibilidad, exigencia que no existe para las sociedades ni para las asociaciones. Si bien ese requisito aparece plausible por estar fundado en asegurar la viabilidad de la iniciativa, se constituye en una imposición que dificulta el trámite sin fundamento legal.

Dificultad adicional para la constitución regular de las cooperativas reside en que el registro de cooperativas está radicado en la ciudad capital del país, con lo cual las distancias que supone el extenso territorio nacional suman inconvenientes. Si bien la ley autoriza que el trámite pueda iniciarse ante el órgano local competente de cada provincia ${ }^{16}$, no siempre tal órgano cuenta con la organización y diligencia adecuadas para llevarlo adelante en coordinación con la autoridad de aplicación.

Las reformas del estatuto como así también los reglamentos que no sean de mera organización interna de las oficinas, deben sometidos a la aprobación de la autoridad de aplicación antes de entrar en vigencia. El trámite que debe seguirse al efecto es semejante al de la constitución de la cooperativa y tropieza con los mismos inconvenientes.

Contra las decisiones de la autoridad de aplicación relacionadas con la autorización para funcionar, los reglamentos y las reformas del estatuto, pueden interponerse recursos administrativo y judicial.

En suma, como ha sucedido tradicionalmente, la LC sujeta el reconocimiento del carácter de persona jurídica a la autorización de un organismo especializado en materia de cooperativas y si bien el trámite resulta económico pues no hay necesidad de intervención notarial ni pago de impuestos, su duración suele ser más extensa de lo previsto por la ley.

\section{Asociados}

La capacidad de las personas humanas (así las llama el Código Civil y Comercial) para ser asociadas de una cooperativa se adquiere con la mayoría de edad (18 años) si bien, conforme con las reglas generales del derecho privado, pueden serlo también los menores por medio de sus representantes legales. De manera que no existen restricciones de orden legal para formar parte de una cooperativa.

16 Acerca del órgano local competente de cada provincia se trata en el capítulo 12, a propósito de la fiscalización pública. 
Asimismo, en la línea de la amplitud existente para las personas humanas, la ley admite que las personas jurídicas, se asocien a las cooperativas. De tal manera que todas las personas jurídicas privadas reconocidas por el Código Civil y Comercial pueden asociarse: sociedades, asociaciones, mutuales, fundaciones, etc. Entre las sociedades la ley menciona expresamente a las sociedades por acciones.

Obviamente, tanto las personas humanas como jurídicas deben reunir los requisitos establecidos por el estatuto. Impera, pues, la autonomía de la voluntad de la cooperativa para establecer dichos requisitos tanto en materia de actividad como territorial, siempre que no se viole el principio del ingreso irrestricto, como también la libre decisión de los interesados en asociarse. Sin embargo, la ley formula una precisión adicional que aclara posibles situaciones de conflicto con el principio del ingreso abierto: puede supeditarse el ingreso a las condiciones derivadas del objeto social. Vale decir que una cooperativa podría limitar el ingreso aun de aquéllos que reúnen los requisitos del estatuto cuando su capacidad de prestación del servicio que constituye el objeto social se encuentre colmada, por ej.: la capacidad para procesar productos en una cooperativa agraria o la capacidad de brindar ocupación en una cooperativa de trabajo.

Una disposición singular de la LC es la que permite la asociación de personas jurídicas públicas: el Estado Nacional, las provincias, los municipios, los entes descentralizados y las empresas del Estado ${ }^{17}$. Esta expresa permisión posibilita que mediante esa asociación se lleven a cabo empresas de interés público en las que coincide el interés de las cooperativas, caso frecuente de las cooperativas de electricidad y otros servicios esenciales como provisión de agua, gas, comunicaciones, etc.

Para materializar esta asociación la ley habilita dos alternativas:

a) asociación en los términos comunes de la LC, es decir en igualdad de condiciones con los demás asociados, o bien

b) convenir con la cooperativa la participación en la administración y fiscalización de sus actividades, siempre que sea coadyuvante a los fines perseguidos y que tales convenios no restrinjan la autonomía de la cooperativa. Esta alternativa posibilita que

17 La posibilidad de asociación con el Estado ha llevado a algunos autores a denominar a estas cooperativas como «cooperativas mixtas» (Althaus, Alfredo A., Tratado de derecho cooperativo, 2. ${ }^{a}$ ed., Zeus, Rosario, 1977, p. 228) pero debe tenerse presente que tal asociación no altera la naturaleza de la cooperativa ni compromete su autonomía. 
los entes públicos realicen inversiones de importancia en la cooperativa con destinos determinados y convengan con ellas una participación — dentro de límites estrictos- que les permita vigilar el cumplimiento de dichos destinos.

No obstante, la ley también permite que los entes públicos utilicen los servicios de las cooperativas sin asociarse a ellas pero con su consentimiento. Tal sucede cuando el ente en cuestión no esté facultado para asociarse o bien considere conveniente no hacerlo, pero en todo caso es necesario el acuerdo de la cooperativa. Sin embargo, hay un caso en el que la cooperativa está obligada a prestar sus servicios a las personas jurídicas públicas, sin el requisito de que se asocien: cuando ella sea la única concesionaria de un servicio público en la localidad donde actúa. En tal supuesto, la cooperativa debe efectuar la prestación del servicio en las mismas condiciones establecidas para sus asociados.

Cabe señalar, no obstante, que en los últimos años se ha ido abriendo camino la exigencia derivada del derecho administrativo de que la cooperativa deba prestar los servicios públicos esenciales a toda persona que lo solicite, sin el requisito de asociarse. De esa manera, en virtud del carácter general y universal del servicio, aquéllos que no se asocian ni aportan capital pueden gozar del servicio en igualdad de condiciones con los asociados, si bien sólo éstos últimos participan en el gobierno de la cooperativa.

El ingreso como asociado puede tener lugar en la asamblea constitutiva mediante la suscripción de cuotas sociales que figure en el acta respectiva o bien durante la vida de la cooperativa mediante solicitud dirigida al consejo de administración el cual debe tratarla y brindar respuesta. De la ilimitación del número de asociados y de la exigencia del libre ingreso, surge la obligación de fundar el eventual rechazo de la solicitud el cual podría dar lugar a una acción judicial por parte del solicitante fundada en incumplimiento de la disposición legal. No parece, en cambio, correcto sostener que el rechazo pueda ser apelado ante la asamblea de la cooperativa pues el tercero rechazado carecería de personería para ocurrir ante ese órgano.

Los derechos básicos de los asociados son los siguientes:

a) uso de los servicios sociales, puesto que su prestación es la razón de ser de la cooperativa;

b) voto en igualdad de condiciones con los demás asociados;

c) retorno sobre las operaciones realizadas con la cooperativa;

d) interés sobre las cuotas sociales integradas, siempre que el estatuto prevea su pago; 

e) acceso al registro de asociados y solicitar al síndico información sobre los demás libros;
f) libre egreso en las condiciones que establezca el estatuto.

Por otro lado, los principales deberes son:
a) suscribir e integrar cuotas sociales conforme establezca el esta- tuto;
b) responder por las obligaciones de la cooperativa hasta el valor de las cuotas sociales suscritas;
c) acatar las resoluciones de la asamblea siempre que fueran con- formes con la ley y el estatuto.

El estatuto debe reglar el retiro y exclusión de asociados. En cuanto al primero, la ley dispone que pueden retirarse voluntariamente en la época establecida en el estatuto o, en su defecto, al finalizar el ejercicio dando aviso con treinta días de anticipación. La exclusión, a su vez, puede ser decidida por el consejo de administración y apelada ante la asamblea en los términos que determine el estatuto en cuanto a los efectos del recurso. A continuación queda expedita la vía judicial contra la resolución de la asamblea. Sobre la devolución del capital en ambos casos se tratará en el capítulo siguiente.

En resumen, la ley respeta con amplitud el principio de libre acceso y adhesión voluntaria y dedica varias disposiciones a la relación con el Estado en el aspecto operativo abriendo puertas a la colaboración público/privada pero preservando estrictamente la autonomía de la cooperativa.

\section{Capital}

En la cooperativa el capital cumple una función instrumental para la realización del objeto social, que es siempre el servicio a los asociados. De manera que, a diferencia de lo que sucede en las sociedades, no se apropia de los resultados de la gestión social ni constituye pauta para la adopción de las decisiones. Conforme con esos lineamientos se trata el tema en la LC.

El capital es eminentemente variable e ilimitado. No existe exigencia de capital mínimo, salvo para bancos cooperativos y cooperativas de seguros en virtud del régimen especial que rige a esas actividades. La variación del capital inicial se produce por el ingreso de nuevos asociados o por el aumento del capital por parte de los existentes. El estatuto determina el capital mínimo para el ingreso pero de allí en más 
los asociados pueden libremente incrementar sus aportes, salvo que el estatuto establezca la obligación de suscribir e integrar capital en proporción con el uso real o potencial de los servicios sociales. Este mecanismo, expresamente autorizado por la LC, permite mantener el capital de la cooperativa en un nivel permanentemente adecuado a la evolución de sus necesidades operativas distribuyendo la exigencia de su formación entre los asociados de manera equitativa.

A su vez, la disminución del capital tiene lugar por el retiro o la exclusión de asociados que conllevan la devolución de sus respectivos aportes $^{18}$. A fin de que estas devoluciones no lesionen el patrimonio social, con el consiguiente perjuicio para la entidad, la ley autoriza que el estatuto limite el reembolso anual de las cuotas sociales a un monto que no exceda el cinco por ciento del capital integrado conforme surge del balance del último ejercicio. Si el monto a devolver fuera superior, los casos que no puedan ser atendidos serán resueltos en los ejercicios siguientes por orden de antigüedad de las renuncias. Las cuotas sociales pendientes de reembolso devengarán un interés equivalente al de los depósitos bancarios en caja de ahorro.

Aspecto de especial relevancia es que el reembolso del capital se efectúa en todos los casos por el valor nominal de las cuotas sociales integradas, deducidas las pérdidas que proporcionalmente les correspondiera soportar. Vale decir que nunca las reservas pueden formar parte del monto a devolver, ni aun en el supuesto de disolución. Este rasgo es característico de las cooperativas.

El capital de la cooperativa se constituye por cuotas sociales indivisibles y de igual valor que se representan en títulos denominados acciones que revisten carácter de nominativas. La ley admite que sean integradas en dinero o en bienes cuya valuación se realice por acuerdo entre el asociado aportante y el consejo de administración, el cual debe ser sometido a la aprobación de la asamblea.

Una novedad introducida en el régimen del capital en la década de 1990, cuando en varios países se admitió que las cooperativas recibieran aportes de capital bajo modalidades diferentes, es el llamado capital complementario reglado por una resolución de la autoridad de apli-

18 La doctrina en general no acepta la devolución parcial del capital aportado por los asociados, si bien la LC no se pronuncia al respecto. Lo que admite la ley es que el consejo de administración pueda ordenar la reducción del capital en proporción al número de cuotas sociales de los asociados (art. 35). Esta disposición no ha tenido aplicación en razón de la inflación y de la constante necesidad de incrementar el capital social. (Farrés Cavagnaro-Menéndez, Cooperativas. Ley 20.337 comentada, anotada y concordada, T. I, Depalma, Buenos Aires, 1987, p. 530). 
cación, circunstancia que ha llevado a poner en duda su legalidad. Se trata de aportes voluntarios de los asociados reembolsables en el plazo que fije la asamblea que resolvió la emisión, la cual debe también establecer el interés que se pagará con la totalidad o parte de los excedentes anuales. Este capital se representa en títulos especiales nominativos y transferibles sólo entre asociados que deben constar en un libro especial.

Cabe señalar que, teniendo en cuenta el carácter persistente de la inflación en el país, la ley autoriza que las cooperativas revalúen sus activos a fin de que los balances exhiban una situación contable más acorde con la realidad económica. Dicho revalúo debe ser realizado conforme con las normas que dicte la autoridad de aplicación y ésta suele tomar en consideración las resoluciones técnicas de la profesión contable. Tales normas disponen que el saldo que surja del revalúo de los activos sea destinado a una reserva -irrepartible como todas - o bien sea capitalizado en cuotas sociales de los asociados. En este último caso no aumenta el valor de las cuotas sociales sino que se emiten nuevas por el valor del saldo de revalúo.

Cuestión que provocó gran inquietud entre las cooperativas fue la incorporación de las normas internacionales de contabilidad (NIIF) en el ámbito local por parte del gremio contable. Dichas normas disponían que el capital de las cooperativas, habida cuenta de su carácter variable, debía ser contabilizado como un pasivo toda vez que se halla sujeto a eventual devolución. De esa manera el patrimonio social quedaba notablemente menguado, al punto de resultar insignificante en muchos casos y, a su vez, el pasivo alcanzaba una magnitud que guardaba una desproporcionada relación con el activo. Una acertada resolución técnica de la organización profesional de los contadores estableció un tratamiento adecuado para el tema. Dicha resolución fue ratificada por la autoridad de aplicación, que cuenta con atribuciones legales para reglamentar la presentación de los estados contables. De esa manera quedó superado el problema y el capital continúa registrándose dentro del patrimonio social ${ }^{19}$.

En fin, salvo por la terminología utilizada, el posible revalúo de las cuotas sociales y la posterior introducción de los llamados títulos cooperativos de capitalización (capital complementario), la regulación del capital sigue los lineamientos tradicionales.

19 Las peripecias de este tema y su solución pueden verse en: Cracogna, Dante, «El capital en las cooperativas y las NIIF», Favier Dubois, Eduardo M. (Director), Derecho Contable Aplicado, Errepar, Buenos Aires, 2018, p. 369 y ss. 


\section{Excedentes, fondos y reservas}

La LC distingue entre excedentes repartibles y no repartibles, distinción que tiene claras consecuencias económicas y jurídicas. Define a los primeros como aquéllos que provengan de la diferencia entre el costo y el precio de los servicios prestados a los asociados; por exclusión, los segundos son todos los demás 20 .

A partir de esta distinción determina el destino de los excedentes repartibles. En primer lugar, el 5\% debe destinarse a reserva legal, la cual seguirá creciendo indefinidamente pudiendo llegar a superar el capital si es que no fuera afectada a enjugar quebrantos una vez consumidas las demás reservas.

En segundo término, otro $5 \%$ se destina a un fondo de acción asistencial y laboral o para estímulo del personal. Este fondo -que no existe en las sociedades - constituye una suerte de participación de los empleados en los resultados de la cooperativa. La ley deja la opción de distribuirlo en dinero o bien dedicarlo a actividades que beneficien a los trabajadores, pero queda claro que, en todo caso, son éstos sus destinatarios. Una reglamentación de la autoridad de aplicación prescribe que este fondo debe ser utilizado en el curso del siguiente ejercicio, es decir que no puede acumularse.

A continuación, otro $5 \%$ se destina al fondo de educación y capacitación cooperativas. Dispone la ley que este fondo se debe invertir anualmente ya sea en forma directa por la propia cooperativa o a través de entidades de grado superior o de instituciones especializadas con personería jurídica, en todos los casos con afectación específica a actividades de educación y capacitación. Adicionalmente, la ley prescribe que la memoria anual del consejo de administración debe informar acerca de la inversión realizada, con indicación de las actividades cumplidas o mención de la cooperativa de grado superior o entidad especializada a la cual se remitieron los fondos respectivos para su aplicación al fin establecido por la ley.

Seguidamente, la ley admite que se destine una suma indeterminada para pagar un interés a las cuotas sociales, siempre que lo autorice el estatuto, el cual no puede exceder en más de un punto al que cobra el Banco de la Nación Argentina en sus operaciones de descuento. De manera que el pago de interés al capital se halla autorizado, si el estatuto lo prevé, pero a una tasa estrictamente limitada.

20 Cracogna, Dante, "La distribución de los excedentes en las cooperativas. Derecho y contabilidad», Doctrina societaria y concursal, n. ${ }^{\circ} 265$, Errepar, diciembre de 2009, p. 1307 y ss. 
Por fin, satisfechos los destinos anteriores, el resto de los excedentes repartibles se destina a la distribución entre los asociados en concepto de retorno en proporción a las operaciones realizadas o los servicios utilizados por cada uno. De esta manera se satisface uno de los caracteres esenciales de las cooperativas: la devolución del excedente a los asociados que han contribuido a su formación en la misma proporción en que cada uno lo haya realizado. En una serie de incisos la ley especifica cómo se calcula esa proporción en las diferentes clases de cooperativas, siempre sobre la base del mismo principio general. Constituye un caso singular el de las cooperativas de crédito en el que se admite que la distribución se efectúe en proporción a las operaciones realizadas o al capital aportado, según lo establezca el estatuto. Esta disposición, que proviene de la anterior ley de cooperativas, se funda en la consideración de que el capital aportado constituye un ahorro de los asociados y que la cooperativa lo promueve brindando el servicio de su administración. De todas maneras, compete al estatuto, como expresión de la voluntad social, determinar la forma de asignar el resultado.

Deslindado el excedente repartible y establecido cuál es su destino, el resto constituye excedente no repartible. Este es el que proviene de dos fuentes: la prestación de servicios a no asociados y las operaciones que no constituyen prestación de servicios a los asociados. Ejemplo de estas últimas sería la venta de un bien del activo fijo que dejara un remanente en relación con su valor o la renta de una inversión no habitual de disponibilidades financieras. Estos excedentes no son repartibles pues no provienen de operaciones realizadas por los asociados; si se les asignaran a éstos, estarían lucrando a costa de los terceros o de operaciones ajenas al servicio específico para el que existe la cooperativa. En consecuencia, tales excedentes deben destinarse a una cuenta de reserva, distinta de la reserva legal.

Dispone la LC que los resultados deben determinarse por secciones, es decir según las diferentes actividades que la cooperativa realice. Por ejemplo, en una cooperativa agraria que realice la provisión de insumos y la comercialización de productos, cada una de esas actividades constituye una sección y los resultados deben determinarse en forma separada para cada una de ellas. De esa manera, los asociados perciben exactamente los retornos que hubieran contribuido a formar con sus respectivas operaciones en cada sección. No obstante, a fin de preservar la unidad patrimonial de la cooperativa, no podrán distribuirse excedentes en una sección hasta haber compensado los quebrantos que la otra hubiera arrojado.

Corresponde a la asamblea cuando considera el balance anual resolver acerca de la forma en que habrán de ser distribuidos el retorno 
y el interés que surjan de aquél (efectivo, acreditación en cuenta, compensación con adquisición de productos, etc.) incluida su distribución total o parcial en cuotas sociales, lo cual constituye un eficaz método de capitalización de la cooperativa.

Las reservas, cualquiera fuese su origen, son irrepartibles y deben permanecer en cuentas claramente individualizadas. Solamente pueden ser utilizadas para compensar eventuales quebrantos comenzando por las provenientes de la prestación de servicios a no asociados y de operaciones no específicas del objeto social, la del saldo de revalúo contable no capitalizado para, finalmente, utilizar la reserva legal. Cuando se hubiera recurrido a las reservas de cualquier clase para enjugar pérdidas no podrán distribuirse excedentes sin haberlas reconstituido al nivel anterior a su utilización, de tal suerte que las reservas solamente pueden crecer pero no disminuir.

La irrepartibilidad de las reservas surge claramente de la exigencia de devolver a los asociados solamente el valor nominal de sus cuotas sociales en caso de retiro o exclusión y aun en el supuesto de disolución de la cooperativa ya que en esta circunstancia el sobrante patrimonial que resultare de la liquidación debe ser destinado al Fisco para promoción del cooperativismo.

En conclusión, el régimen de determinación del resultado, como así también su distribución y la formación de reservas irrepartibles y la constitución y aplicación del fondo de educación cooperativa son congruentes con los principios cooperativos.

\section{Estructura orgánica}

La LC adopta un régimen de organización interna de la cooperativa compuesto de tres órganos necesarios, a cada uno de los cuales asigna una función específica21: la asamblea es el órgano de gobierno; el consejo de administración a cargo de la administración de la cooperativa y la sindicatura —unipersonal o plural- encargada de la fiscalización privada ${ }^{22}$. Este modelo de organización del gobierno cooperativo rige

21 Este modelo es el vigente prácticamente en todos los países latinoamericanos y es el que adopta el Proyecto de Ley Marco para las Cooperativas de América Latina (Alianza Cooperativa Internacional para las Américas, San José de Costa Rica, 2009).

22 La denominación de "síndico» y la posibilidad de que sea unipersonal constituyen característica singular de la legislación argentina pues, por lo general, en los demás países de la región el órgano de fiscalización privada es de composición plural y se denomina «junta fiscalizadora». 
para todas las cooperativas, cualquiera fuere su objeto social específico y su grado (primaria, federación o confederación). Una característica relevante consiste en que en todos los casos dichos órganos están integrados por asociados; no se admite que quienes no invistan la condición de asociados puedan integrar la estructura orgánica de la cooperativa aunque sí pueden desempeñar otras funciones: gerentes, empleados, asesores, auditores, etc.

\subsection{Asamblea}

La asamblea es el órgano que expresa por excelencia la democracia cooperativa puesto que ella está formada por todos los asociados que voluntariamente quieran participar, en la cual cuentan exclusivamente con un solo voto cada uno independientemente de la cantidad de cuotas sociales que posean, salvo el caso de las cooperativas de grado superior a las que se hará referencia en el capítulo sobre integración. Sin perjuicio de que cada órgano tiene sus funciones específicas asignadas por la ley, la asamblea cuenta con precedencia sobre los demás toda vez que es la asamblea la que da origen a la cooperativa (asamblea constitutiva) y es ella la que designa y eventualmente remueve a los integrantes de los demás órganos y juzga su actuación mediante la consideración de sus respectivos informes.

La asamblea se reúne ordinariamente un vez por año dentro de los cuatro meses del cierre del ejercicio económico para considerar el informe del consejo de administración (llamado memoria) y los estados contables juntamente con los informes del síndico y del auditor. Además de estos asuntos trata la elección de los integrantes del consejo de administración y de la sindicatura, sin perjuicio de considerar todo otro asunto incluido en el orden del día.

La asamblea extraordinaria se reúne para considerar cualquier otro asunto toda vez que lo disponga el consejo de administración por sí, por pedido del síndico o a solicitud de asociados cuyo número equivalga por lo menos al 10\% del total, salvo que el estatuto exigiera un porcentaje menor. De manera que la distinción entre asamblea ordinaria y extraordinaria tiene en las cooperativas rasgos diferentes de los que las caracterizan en las sociedades.

Está reservada a la asamblea la consideración de memoria; estados contables; informes de síndico y auditor; distribución de excedentes; fusión o incorporación; disolución; cambio de objeto social; asociación con personas de otro carácter jurídico; asociación de personas jurídicas públicas cuando se convenga su participación en los órganos de admi- 
nistración y fiscalización; designación y remoción de consejeros y síndicos; reforma del estatuto; aprobación y reforma de reglamentos internos e integración en cooperativas de grado superior. El estatuto puede reservar a la competencia de la asamblea la consideración de otros asuntos, además de los indicados.

La convocatoria de la asamblea debe realizarse con una anticipación mínima de quince días incluyendo el orden del día respectivo y comunicarse de igual manera a la autoridad de aplicación. El quorum para sesionar válidamente requiere la presencia de la mitad más uno de los asociados pero pasada una hora desde la fijada en la convocatoria puede reunirse válidamente cualquiera sea el número de presentes. Las resoluciones son válidas con la mayoría simple de los asociados presentes, salvo los asuntos para los que el estatuto requiera una mayoría especial. La ley exige dos tercios, siempre de los asociados presentes, para resolver el cambio del objeto social, la fusión o incorporación y la disolución. Las normas sobre quorum y mayoría resuelven de manera práctica estas cuestiones evitando la inmovilización de la asamblea.

Debido a las restricciones impuestas por la pandemia del coronavirus y con fundamento en el Código Civil y Comercial la autoridad de aplicación autorizó que las asambleas se realicen por vía remota, sujeto al cumplimiento de recaudos que garanticen la accesibilidad de los asociados y la conservación de las actuaciones. Cuando el estatuto exija el voto secreto, cosa que suele ocurrir con la elección de consejeros y síndicos, el sistema utilizado debe asegurar su implementación. Este régimen de asambleas remotas seguramente habrá de ser continuado una vez finalizada la pandemia, pero será necesario introducirle algunas adecuaciones aconsejadas por la experiencia de su aplicación.

Se permite el voto por poder, salvo que el estatuto lo prohíba. El mandato debe recaer en un asociado quien no puede representar a más de dos. De esa manera se evita la intervención de terceros en la asamblea y la acumulación de votos. El derecho de receso es solamente admitido cuando se resuelva el cambio sustancial del objeto social. Los ausentes o quienes votaron en contra pueden ejercerlo dentro de los treinta días y el reembolso de sus cuotas sociales se efectuará dentro de los noventa días.

Las resoluciones asamblearias —siempre que sean conformes con la ley, el estatuto y el reglamento- son obligatorias para todos los asociados pero en caso de violación de la ley, el estatuto o el reglamento pueden ser impugnadas judicialmente ante el juez competente dentro de los noventa días de la clausura de la asamblea. Son titulares de este derecho los consejeros y los síndicos, la autoridad de aplicación y los asociados ausentes o que no hubieran votado favorablemente. 
Situación especial que contempla la ley es la de cooperativas cuyo número de asociados supera los cinco mil en cuyo caso la asamblea estará formada por delegados elegidos en asambleas de distritos conforme con las disposiciones que establezcan el estatuto o un reglamento. Las asambleas de distrito solamente eligen los delegados respectivos y pueden brindar información pero no existe posibilidad de otorgar mandatos imperativos ya que si lo hicieran la asamblea general se limitaría a un recuento de votos sin genuina deliberación. Los delegados duran un año en sus cargos, de manera que pueden participar en las asambleas extraordinarias que eventualmente se realicen pero deben elegirse nuevos para la siguiente asamblea ordinaria. La ley admite que el estatuto establezca un sistema similar para la representación de asociados residentes en lugares distantes del de la asamblea sobre la base de un régimen de igualdad para todos los distritos. Cabe señalar que igualdad no significa igualdad matemática sino un régimen que tenga las mismas bases. La asamblea de delegados constituye una modalidad común habida cuenta de la existencia de numerosas cooperativas que superan la cantidad mínima de asociados y en las cuales la participación directa de ellos resultaría difícil o aun imposible.

\subsection{Consejo de administración}

La LC prevé un sistema unitario de administración a cargo de un órgano integrado por no menos de tres asociados. Este número se basa en que para constituir una cooperativa es necesario un mínimo de diez asociados $^{23}$ y en el criterio de que un consejo plural que funcione en colegio resulta más adecuado para la conducción de los asuntos de la cooperativa.

Los consejeros - como los llama la ley- son elegidos por la asamblea con una duración no mayor de tres ejercicios en sus cargos pero pueden ser reelegidos salvo prohibición expresa del estatuto. De manera que en este punto — reelegibilidad o no- que suele ser materia de controversia, ha de estarse a lo que el estatuto de cada cooperativa disponga.

23 La facultad legal otorgada a la autoridad de aplicación de autorizar la constitución de cooperativas con menos de diez asociados, sumada a la proliferación actual de cooperativas de trabajo con reducido número de asociados, torna problemática la exigencia de un consejo de administración de composición plural con no menos de tres miembros. 
El consejo de administración tiene una competencia amplia para el ejercicio de sus funciones pues no sólo cuenta con las atribuciones que fije el estatuto sino también todas las necesarias para la realización del objeto social. Se consideran implícitas todas aquellas facultades que la ley, el estatuto o el reglamento no reservaran expresamente a la asamblea $^{24}$. Sus reglas de funcionamiento quedan libradas al estatuto pero se exige que se reúna por lo menos una vez al mes y que sesione con más de la mitad de sus miembros. También en este caso -al igual que con relación a la asamblea - la autoridad de aplicación reglamentó la realización de reuniones a distancia respetándose los requisitos que ella establece, lo cual ha venido a agilizar notablemente la actuación de este órgano. Seguramente el método de reuniones virtuales habrá de ser continuado una vez superada la pandemia.

La representación legal de la cooperativa corresponde al presidente, si bien el estatuto puede autorizar la actuación de más consejeros. Por otra parte, la ley autoriza que la asamblea fije remuneración a los consejeros por las tareas efectivamente realizadas en el desempeño de su actividad, lo cual vino a zanjar una antigua disputa existente al respecto.

Los consejeros responden por el incumplimiento de la ley, el estatuto y el reglamento pero pueden eximirse mediante prueba de no haber participado en la reunión que adoptó la resolución impugnada o mediante la constancia de su voto en contra. No pueden realizar actividades en competencia con la cooperativa ni participar en la decisión de asuntos en los que tuvieran un interés contrario.

Por fin, el consejo de administración puede designar de su seno un comité ejecutivo para atender los asuntos ordinarios de la administración, práctica que es corriente. Además, puede nombrar gerentes, sin que ello altere las responsabilidades de los consejeros. Los gerentes son empleados nombrados y removidos por el consejo de administración.

\subsection{Sindicatura y auditoría}

La LC impone la existencia de un órgano específico de fiscalización privada a cargo de uno o más asociados llamados síndicos, elegidos por la asamblea. Si fueran más de uno el estatuto debe fijar un número impar no menor de tres que funcionarán como cuerpo colegiado bajo la

24 Verón, Alberto Víctor, Tratado de las cooperativas, T. II, La Ley, Buenos Aires, 2009, p. 3. 
denominación de comisión fiscalizadora y llevará un libro de actas. La experiencia demuestra que raramente la sindicatura es plural. Al igual que en el caso de los consejeros la duración del cargo no puede exceder de tres ejercicios; sin embargo, a diferencia de aquéllos, solamente pueden ser reelegidos si lo autoriza el estatuto.

Los síndicos pueden ser retribuidos por resolución de la asamblea y son legalmente responsables por el incumplimiento de sus obligaciones. Deben documentar sus actuaciones y, si formularan observaciones, una vez agotada la gestión interna, deben informar a la autoridad de aplicación, con lo cual cubren la responsabilidad de su deber de fiscalización.

La ley asigna a los síndicos amplias atribuciones para el cumplimiento de su función de fiscalización que es siempre de legalidad, es decir de contralor del cumplimiento de la ley, el estatuto y el reglamento por parte del consejo de administración. No pueden interferir en las decisiones de dicho órgano en tanto ellas no exorbiten el marco legal. Claramente se establece que deben ejercer sus funciones de modo que no entorpezcan la regularidad de la administración social.

A efectos del ejercicio de su función de fiscalización tienen atribuciones para examinar los libros sociales; verificar el estado de caja y existencia de valores; asistir con voz a las reuniones del consejo de administración; facilitar el ejercicio de los derechos de los asociados; informar por escrito a la asamblea ordinaria sobre los documentos que presente el consejo de administración; convocar a asamblea extraordinaria, previo requerimiento al consejo de administración; hacer incluir asuntos en el orden del día de la asamblea; etc.

Adicionalmente la ley exige que todas las cooperativas cuenten con un servicio de auditoría externa a cargo de contador público inscripto en la matrícula profesional de la respectiva jurisdicción. Esta auditoría complementa la labor de fiscalización que realiza la sindicatura, pero es de carácter técnico contable. Puede ser realizada por cooperativa de grado superior o entidad especialmente constituida a ese fin, pero siempre por medio de un contador profesional. La LC permite que la auditoría sea desempeñada por el síndico cuando éste reúna la calidad profesional indicada, en cuyo caso la misma persona -asociado de la cooperativa - desempeñará la dos funciones. El auditor debe confeccionar informes trimestrales de acuerdo con la reglamentación dictada por la autoridad de aplicación, los cuales deben ser transcriptos en un libro especial.

Cuando la cooperativa lo solicite y su situación económica lo justifique, la auditoría será prestada por el órgano local competente en 
forma gratuita y si no se prestara la cooperativa estará exenta de responsabilidad.

La organización interna tripartita con participación exclusiva de los asociados y la exigencia de contar auditoría externa constituyen rasgos relevantes del gobierno cooperativo.

\section{Integración}

La LC dedica un capítulo especial a la cooperación entre cooperativas, a tono con la importancia adjudicada a este tema mediante su incorporación al plexo de los principios cooperativos en 1966 y mantenido en la Declaración sobre la Identidad Cooperativa ${ }^{25}$. Ello sin perjuicio de otras modalidades previstas en la legislación general, como se verá más adelante.

A efectos de su implementación conforme con las necesidades y características de cada circunstancia, la ley establece varias opciones libradas a la voluntad de las cooperativas. En primer lugar, establece que ellas pueden asociarse entre sí para el mejor cumplimiento de sus fines, lo cual significa que una cooperativa de consumo puede asociarse a una de seguros para cubrir sus riesgos o que una cooperativa de trabajo puede asociarse a un banco cooperativo para atender sus necesidades financieras o que una cooperativa de vivienda puede asociarse a una de electricidad, etc. Es decir que existe total amplitud en esta materia, incluyendo asociaciones recíprocas cuando fuera del caso.

La realización de una o más operaciones en común puede asimismo ser convenida entre dos o más cooperativas las que determinarán cuál de ellas será la representante de la gestión y asumirá la responsabilidad frente a terceros. Se trata de una variante de la sociedad accidental o del contrato en participación, actualmente legislado en el Código Civil y Comercial.

En tercer lugar, se prevé la fusión entre cooperativas cuando sus respectivos objetos sociales fueran comunes o complementarios. Esta es la forma extrema de integración puesto que una o más cooperativas se disuelven sin liquidarse para incorporarse a otra o bien todas se disuelven sin liquidarse para dar lugar al nacimiento de una nueva cooperativa resultante de la fusión.

25 El principio de integración, o de cooperación entre cooperativas, fue formalmente incorporado plexo de los principios por el Congreso de la $\mathrm{ACl}$ realizado en Viena en 1966 y ratificado por la Declaración sobre la Identidad Cooperativa aprobada por la $\mathrm{ACl}$ en el Congreso del Centenario (Manchester, 1995) como 6. ${ }^{\circ}$ principio. 
Por fin, una especial atención está dedicada a la regulación de la llamada integración federativa, es decir aquélla que tiene lugar entre cooperativas de un mismo grado para dar origen a una de grado superior (cooperativas primarias que crean una federación o federaciones que constituyen una confederación). La ley no diferencia entre integración económica e integración representativa, como suele ocurrir en otras legislaciones, admitiendo que la integración se realice para objetivos económicos, culturales o sociales. Ello permite la existencia de federaciones puramente representativas o solamente de carácter económico o que realizan ambas actividades ${ }^{26}$. En tanto cooperativas, todas se rigen por las disposiciones de la ley con sólo las modificaciones específicas establecidas para ellas, básicamente en cuanto al número mínimo de asociadas — deben ser siete-y el régimen de voto. Este último admite distintas variantes: un voto por cooperativa; voto proporcional a la cantidad de asociados con que cada cooperativa cuente; voto proporcional al volumen de las operaciones realizadas por cada cooperativa con la federación; o bien una fórmula que combine los dos últimos elementos (número de asociados y volumen de operaciones). Corresponde al estatuto establecer el régimen respectivo, pero siempre sujeto a la fijación de un mínimo y de un máximo que aseguren la representación de todas las asociadas e impidan el predominio excluyente de alguna de ellas. Las variantes legales posibilitan que cada entidad de grado superior adopte un sistema adecuado a sus características; por ejemplo una federación con actividad económica podrá establecer el voto en proporción a las operaciones, en tanto que otra de carácter representativo podrá hacerlo en relación con el número de asociados.

Además de las formas de integración previstas en la LC, las cooperativas pueden también adoptar otras que la legislación brinda a las personas jurídicas en general, como es el caso de los contratos asociativos previstos en el Código Civil y Comercial, a saber: negocio en participación, semejante a las operaciones en común previstas en el capítulo sobre la integración cooperativa; agrupaciones de colaboración; uniones transitorias y consorcios de cooperación. A ello debe sumarse la libertad para configurar estos contratos con otros contenidos, tal como autoriza el art. 1446 del mencionado Código.

También pueden las cooperativas acudir a la constitución de sociedades entre sí cuando ello fuera del caso — por ejemplo, para realizar actividades legalmente reservadas a sociedades en forma exclusiva-

26 La experiencia argentina en materia de integración es muy variada; las manifestaciones más antiguas datan de las primeras décadas del siglo xx y fueron desarrollándose de manera sostenida desde entonces, tanto en materia económica como representativa. 
siempre que observen los recaudos que exige la LC: que sea conveniente para su objeto social y no desvirtúen su propósito de servicio.

En síntesis, la integración cooperativa está prevista con amplitud y de manera flexible, a tono con la tradición que existe en la experiencia nacional desde antes de la sanción de la primera ley de cooperativas.

\section{Disolución}

Procede la disolución voluntaria de la cooperativa mediante decisión de la asamblea con el voto favorable de dos tercios de los asociados presentes. La disolución es forzosa cuando el número de asociados se reduzca por debajo del mínimo legal durante un período superior a seis meses y cuando le fuera retirada la autorización para funcionar conforme con las disposiciones de la LC o cuando corresponda en virtud de otras disposiciones legales, por ejemplo las del régimen de las entidades financieras y de seguros. Asimismo, se disuelven las cooperativas que se fusionen para dar nacimiento a una nueva o las que se incorporen a otras.

Por otro lado, corresponde señalar que las cooperativas se encuentran sujetas al régimen de la Ley de Concursos y Quiebras que rige para las personas jurídicas en general. De manera que pueden solicitar el concurso de sus acreedores cuando se hallen en cesación de pagos y continúan en existencia si el proceso resulta favorable o bien pueden ser declaradas en quiebra si el concurso fracasa. Igualmente, pueden solicitar directamente su propia quiebra o solicitarla sus acreedores cuando se produce la cesación de pagos ${ }^{27}$.

La consecuencia inmediata de la disolución es la liquidación, es decir el proceso de realización del activo y el pago del pasivo hasta donde el producido alcance, salvo en los casos de fusión e incorporación. El órgano a cargo de la liquidación, excepto en la quiebra y liquidación conforme con regímenes especiales (bancos y seguros), es el consejo de administración; en su defecto corresponde que la asamblea designe liquidadores dentro de los treinta días de la disolución y si éstos no se hacen cargo, cualquier asociado puede solicitar al juez competente la designación de otros.

Dentro de los treinta días de haber asumido el cargo los liquidadores deben confeccionar un balance que someterán a la asamblea den-

27 Cracogna, Dante, "Las cooperativas frente al concurso y la quiebra», Jurisprudencia Argentina, T. 2015-II, p. 17 y ss. 
tro de los treinta días subsiguientes y deben informar al síndico, por lo menos trimestralmente, sobre la marcha del proceso de liquidación. Si la liquidación se prorroga deben confeccionar, además, balances anuales.

Una vez extinguido el pasivo social los liquidadores deben confeccionar el balance final que será sometido a la asamblea con informes del síndico y del auditor y se remitirá a la autoridad de aplicación. Una vez aprobado ese balance se reembolsará a los asociados el valor nominal de sus cuotas sociales integradas, deducida la parte proporcional de los quebrantos si los hubiera. Cumplido ello, si resultara un remanente de la liquidación será destinado al Fisco de la jurisdicción respectiva para promoción del cooperativismo. De manera que en ningún caso los asociados pueden apropiarse de una suma que supere el valor nominal de sus cuotas sociales, lo cual expresa la irrepartibilidad de las reservas. El mismo destino tendrán los importes no reclamados una vez transcurridos tres años sin haber sido retirados.

Finalizada la liquidación se cancelará la inscripción de la cooperativa en el registro que lleva la autoridad de aplicación.

Los aspectos relevantes de la disolución y liquidación consisten en la aplicación de la Ley de Concursos y Quiebras, cuando proceda, y el destino desinteresado del sobrante patrimonial una vez devuelto el valor nominal de las cuotas sociales.

\section{Fiscalización pública28}

La fiscalización pública de las cooperativas se encuentra a cargo de la autoridad de aplicación que es actualmente el Instituto Nacional de Asociativismo y Economía Social (INAES) que funciona en el ámbito del Ministerio de Desarrollo Productivo ${ }^{29}$. La fiscalización puede ser ejercida en forma directa por el INAES o mediante acuerdo con el órgano com-

28 En otros países de la región se suele hablar de «supervisión» en lugar de fiscalización. Por otra parte, las modalidades de esta actividad y los organismos encargados de realizarla son diversos. Ver al respecto: Fici, Antonio, «Tendencias y perspectivas del derecho cooperativo en el contexto global y la supervisión como oportunidad para el sector de la economía social», Boletín de la Asociación Internacional de Derecho Cooperativo, n. ${ }^{\circ} 49$, Deusto, 2015, p. 240 y ss.

29 Originalmente la LC estableció que el Instituto Nacional de Acción Cooperativa (INAC) sería la autoridad de aplicación pero a lo largo del tiempo dicho organismo fue cambiando de denominación y mudando de ministerio hasta llegar en el momento actual al INAES, radicado en el área del Ministerio de Desarrollo Productivo. 
petente de cada provincia ${ }^{30}$, lo cual posibilita una mayor proximidad con las cooperativas de las distintas jurisdicciones dentro del extenso territorio nacional. Sin embargo, tal fiscalización no obsta a la que corresponda por razón del objeto social propio de cada cooperativa, lo cual es particularmente importante en el caso de las financieras y de seguros.

La LC atribuye amplias facultades a la fiscalización pública, tales como requerir documentación; realizar inspecciones; asistir a las asambleas y convocarlas en determinados casos; solicitar al juez competente la suspensión de resoluciones de los órganos sociales y la intervención de las cooperativas cuando ellas realicen actos contrarios a la ley o que importen riesgo para su existencia. No obstante, la ley impone no entorpecer la regular administración de las cooperativas con el ejercicio de la fiscalización.

El uso indebido de la palabra "cooperativa» se halla expresamente prohibido por la LC y su transgresión tiene prevista sanción de multa y clausura de los establecimientos y oficinas de la infractora mientras no se suprima. Su aplicación se encuentra a cargo de la fiscalización pública.

Para el desempeño de la fiscalización la autoridad de aplicación cuenta con la facultad de imponer sanciones de apercibimiento y multas e, incluso, retirar la autorización para funcionar. En todos los casos, las sanciones deben ser aplicadas previo sumario en el que se asegure el derecho de defensa de la cooperativa. Las multas y el retiro de la autorización para funcionar son apelables ante la justicia. El importe de las multas debe destinarse a promoción de las cooperativas.

Como se señaló en el capítulo 5, el INAES tiene a su cargo, además de la fiscalización pública, el registro nacional y también el fomento de las cooperativas, con especial atención a los sectores menos desarrollados. Su dirección se halla a cargo de un directorio compuesto por miembros designados por el Poder Ejecutivo, algunos en forma directa y otros a propuesta de las organizaciones más representativas del movimiento cooperativo. La LC también prevé un consejo consultivo honorario constituido por representantes de los ministerios vinculados con las cooperativas y de las organizaciones representativas de la cooperativas, aunque este cuerpo sólo ha funcionado en breves períodos.

Los recursos con que cuenta el organismo son los que le asigna el presupuesto de la Nación y los que provienen de una contribución es-

30 El órgano local competente, conforme determina la LC, es el que cada provincia establezca para entender en materia cooperativa en su respectiva jurisdicción. El INAES ha ido celebrando convenios con ellos para el ejercicio de la fiscalización pública. 
pecial que las cooperativas deben tributar tomando como base su patrimonio según la fórmula establecida por la Ley 23.427. Los recursos provenientes de esta contribución se coparticipan con las provincias.

La singularidad de la fiscalización pública consiste en que está a cargo del mismo organismo que realiza el registro y la promoción de las cooperativas, en cuya dirección participan representantes del movimiento cooperativo.

\section{Conclusión}

La LC ha probado su utilidad a lo largo de casi cinco décadas debido a su amplitud, flexibilidad y apego a la doctrina cooperativa que permitieron a las cooperativas ir adaptándose a las cambiantes circunstancias sin perder su esencia. De todas maneras hay aspectos que requieren adecuación: simplificación de trámites; tratamiento de las pequeñas cooperativas y la regulación específica de las cooperativas de trabajo que se han expandido notablemente.

Por otro lado, materias que no son propias de la LC pero que inciden sobre las cooperativas también han menester de adecuación, tales como el régimen fiscal, la regulación del crédito cooperativo y el tratamiento de las cooperativas de servicios públicos.

\section{Bibliografía}

Alianza Cooperativa Internacional, Nuevos enfoques de los principios cooperativos en el mundo, Idelcoop, Rosario, 1981.

Alianza CoOperativa InTERnacional, Los principios cooperativos para el siglo XXI, Intercoop, Buenos Aires, 1996.

Alianza Cooperativa Internacional para las Américas, Proyecto de Ley Marco para las Cooperativas de América Latina, San José de Costa Rica, 2009.

Alfonso SÁnChez, Rosalía, «Los principios cooperativos como principios configuradores de la forma social cooperativa», Revista Jurídica de Economía Social y Cooperativa, n. ${ }^{\circ}$ 27, CIRIEC-España, Valencia, diciembre de 2015.

Althaus, Alfredo A., Tratado de derecho cooperativo, 2. ${ }^{a}$ ed., Zeus, Rosario, 1977, p. 228.

AtXABAL RADA, Alberto, «La identidad cooperativa como justificación de un tratamiento fiscal diferenciado», Boletín de la Asociación Internacional de Derecho Cooperativo, n. ${ }^{\circ}$ 50, Deusto, 2016.

CRACOGNA, Dante, "La distribución de los excedentes en las cooperativas. Derecho y contabilidad», Doctrina societaria y concursal, n. ${ }^{\circ} 265$, Errepar, diciembre de 2009. 
CRAcogna, Dante, «El capital en las cooperativas y las NIIF», Favier Dubois, Eduardo M. (Director), Derecho Contable Aplicado, Errepar, Buenos Aires, 2012.

CRACOGNA, Dante, "Las cooperativas frente al concurso y la quiebra», Jurisprudencia Argentina, T. 2015-II.

CRACogna, Dante, "Las cooperativas en el marco del Código Civil y Comercial», Revista de Derecho Comercial y de las Obligaciones, n. ${ }^{\circ} 273$, Buenos Aires, julio-agosto de 2015.

Farrés Cavagnaro-Menéndez, Cooperativas. Ley 20.337 comentada, anotada y concordada, T. I, Depalma, Buenos Aires, 1987.

$\mathrm{FICl}$, Antonio, "Tendencias y perspectivas del derecho cooperativo en el contexto global y la supervisión como oportunidad para el sector de la economía social», Boletín de la Asociación Internacional de Derecho Cooperativo, n. ${ }^{\circ}$ 49, Deusto, 2015.

MünKNER, Hans-H., "Germany», Cracogna, Dante-Fici, Antonio-Henrÿ, Hagen (Editors), International Handbook of Cooperative Law, Springer, Heidelberg, 2013.

PASTORINo, Roberto Jorge, Orígenes del Derecho Cooperativo argentino, Intercoop, Buenos Aires, 1998.

Rezzónico, Alberto Edmundo, «El acto cooperativo. Noción, contenido y alcances. Su incorporación al derecho positivo nacional», Congreso Continental de Derecho Cooperativo. Montevideo, 16-18 de noviembre de 2016, Intercoop, Buenos Aires, 2018.

Rodríguez Gomes, Federico, La sociedad cooperativa, 2. ${ }^{\text {a }}$ ed., Hachette, Buenos Aires, 1955.

VALLATI, Jorge Armando, "El acto cooperativo. Recepción legislativa y jurisprudencial. Efectos en la cooperativa de consumo», Congreso Continental de Derecho Cooperativo. San José de Costa Rica, 20 al 22 de noviembre de 2019, Cooperativas de las Américas, San José, 2020.

VARGAS VASSEROT, Carlos, «El acto cooperativo en el derecho español», Revista Jurídica de Economía Social y Cooperativa, n. ${ }^{\circ} 37$, CIRIEC-España, Valencia, diciembre 2020.

Verón, Alberto Víctor, Tratado de las cooperativas, T. II, La Ley, Buenos Aires, 2009. 


\section{Derechos de autor}

La revista Deusto Estudios Cooperativos es una revista de acceso abierto lo que significa que es de libre acceso en su integridad inmediatamente después de la publicación de cada número. Se permite su lectura, la búsqueda, descarga, distribución y reutilización legal en cualquier tipo de soporte sólo para fines no comerciales y según lo previsto por la ley; sin la previa autorización de la Editorial (Universidad de Deusto) o el autor, siempre que la obra original sea debidamente citada (número, año, páginas y DOI si procede) y cualquier cambio en el original esté claramente indicado.

\section{Copyright}

The Deusto Journal of Cooperative Studies is an Open Access journal which means that it is free for full and immediate access, reading, search, download, distribution, and lawful reuse in any medium only for non-commercial purposes, without prior permission from the Publisher or the author; provided the original work is properly cited and any changes to the original are clearly indicated. 